\section{STRENGTH THROUGH MISERY?}

THE British Association seems to have had a successful meeting this year, and there is nobody who will be sorry. A great many people with puritan inclinations will, however, be delighted to observe that adversity seems to have brought out the best in the association. It is several years now since the association suffered its chronic penury in silence. Instead, it has taken to complaining that the British Government does not reward it properly for doing what is in the last resort a public service-the provision of a lecture service for young people. More recently still, the association has been dropping hints that if the Government does not pay up, the public service will have to go by the board. But this quite proper concern with the health and otherwise of the balance sheet seems to have spurred the association to a wider consideration of the foundations of its continued existence. One way and another, it seems to have resolved that if the world will not give it a living, it must make one for itself. That is a healthy state of mind.

These, however, are only the beginnings of change. The association is still bound in many ways to the traditions of another century. The annual meeting remains partly-not entirely-an anachronism. It covers too much ground and is too didactic. Triviality is being chased away, but there is still some way to go. Nobody is quite sure what purposes are served by the meeting, although most of those who participate enjoy themselves. There is a danger that the indiscriminate encouragement of good works will persuade the association into the encouragement of mediocrity, which implies that there should be some kind of hurdle, however innocuous, to improve the quality of what voung people are invited to exhibit in what is called the science fair. There is also a case for a deliberate erosion of the sense of comradeship which sometimes divides the old hands from those who have only recently joined the association, which implies that there might be great profit in some kind of system under which certain officers of the association were elected-one man, one vote-by card-carrying members. As things are, the association must be unique among modern institutions in not offering those who pay to belong any sense, as of right, of influencing the course of events. Anyway, throw the presidency open to election? That would kill a dozen birds with the same stone. In its attempts to import real live public issues into its proceedings, the association has not been entirely successful-which is no reason for going back to platitudes. There is a great deal that the association could do as a lightning conductor for public controversy.

But is it really wise to let everything depend on the success of the annual meeting? That is a question the association has been asking itself for several years. The answer is no, which is why the association has been trying to diversify its activities. Its lecture service for young people (and adults) has been a moderate but not an outstanding or even an indispensable success, but this now seems threatened by the lack of money. This is inevitable. The association cannot hope to win its reputation by spotting tasks that other people should already have undertaken and then assure its survival by being paid to carry them out. Rather, it must expect to live by its wits, starting up new projects and then handing them over to others to finish off. This is why, in the long run. it will be best if the association can struggle back towards a conception of its public function much more like the one it used to carry out a century ago, when it used to startle its contemporaries with perceptive and authoritative studies of urgent problems inseparable from or occasioned by the growth of science. The association could do worse than become a writer and distributor of tracts. The association would have to learn somehow to escape from the convention of good manners which at present inhibits it, but it would discover that independence is cheap and exhilarating as well

\section{COSMOLOGY TO PLAY WITH}

THE discovery in the past few years of the cosmic black-body radiation may not be a final proof that one kind of cosmology is preferable to another, for it is still not beyond the bounds of possibility that the advocates of steady-state theories will somehow be able to turn the tables on their rivals, but it has already proved to be a powerful stimulus to productive speculation. The calculation by Dr K. C. Jacobs which appears on page 1156 is one valuable illustration of how curiosity has been fired by the recognition that the universe appears to be filled with microwave radiation corresponding to a temperature of about $3^{\circ} \mathrm{K}$. Jacobs sets out to construct a realistic model of a universe which, starting from a dense concentration, is largely dominated by radiation for the first 2,000 vears of its existence. Thereafter, matter and radiation are not strongly in interaction with each other. To begin with, of course, the outward movement of the matter of which his model is composed is rapid but rapidly decelerating. As time goes on, the deceleration itself diminishes. This sequence of events is a more plausible version of the kind of model obtained when a universe dominated by radiation is joined discontinuously to one dominated by the presence of matter. The numbers in the model which Jacobs has constructed are less immediately of importance than the possibility that a universe in which there is a transition for a rapidly decelerating to a less rapidly decelerating universe might account for the way in which the red-shifts of quasars seem to be bunched around certain values. In other words, there is a possibility that models like these may yet be put to some kind of test. 